\title{
Analysis of Dietary Patterns, Intake, Output Performance, and Blood Lactate Concentration according to Athlete Career : A Study on Elite Korean Wrestlers
}

\author{
Yun seok Lee, Dong Ryul Lee, Hyun jong Baik ${ }^{\mathrm{a}}$, Jae hyun Cho ${ }^{\mathrm{a}}$, \& Jun young Sung ${ }^{\mathrm{b}}$ \\ ${ }^{a}$ Ph.D, Department of Physical Education, YongIn University, 134, Yongindaehak-ro, Cheoin-gu, Yongin-si, \\ Gyeonggi-do, Republic of Korea. \\ ${ }^{b}$ Assistant professor, Department of Aero Fitness, Republic of Korea Air Force Academy, 635, Danjea-ro, \\ Nail-myeon, Sangdang-gu, Cheongju-si, Chungcheongbuk-do, Republic of Korea.
}

\begin{abstract}
The aim of this study was to assess the eating habits of Korean wrestlers, and to explore the impact of differences in dietary intake on power output performance and blood lactate concentrations. Thirty adult wrestlers with more than seven years of experience each were included, grouped according to their competitive level (national, senior, and university team level). Participants recorded their dietary intake for seven days; nutritional analysis was performed using the CAN-Pro 4.0 software. After the nutritional survey, power output performance (Wingate test) was evaluated and blood parameters, including lactate concentration, were assessed. The wrestlers' dietary assessments revealed differences in carbohydrate, protein, and fat intake among the groups, as well as differences in the peak power, mean power, and change in peak power, obtained from the Wingate test. Finally, the senior group had a significantly higher and lower lactate concentration than the university group immediately post training and 30 minutes post training, respectively. Follow-up studies should reveal more accurate associations between nutritional intake, nutritional quality, and performance. Finally, considering a study concerning nutrition and weight loss based on the results from this study, including not only wrestlers but also combat sport athletes will benefit nutrition education as well as athletes' intake and performance.
\end{abstract}

Key words: Detary intake; Pwer output; Wingate test; Bood lactate; Ntrition education

\section{Introduction}

Sports nutrition involves the fields of sports medicine, sports science, dietetics, cultural influences,

Submitted : 8 November 2021

Revised : 22 December 2021

Accepted : 27 December 2021

Correspondence : sjy7067@gmail.com and even popular media. Regarding dietary recommendations for elite athletes, nutritionists, registered dietitians, sports scientists, physicians, and other healthcare professionals often debate what constitutes the ideal diet (Vitale \& Getzin, 2019). Sports nutrition however, as stated above, is not merely a concept concerning the athlete's diet, but rather one that 
includes an interdisciplinary approach with respect to various aspects of the athlete and the relevant sport, such as nutrition, exercise, and rest and recovery between the preparation for a competition and the end of the competition. Therefore, the nutritional management of the athlete preparing for competition can affect their performance.

Recently, awareness of the importance of nutritional management in improving an athlete's performance has been increasing, and various studies related to diet and exercise functions have been conducted. However, limited data are available on the adequacy of dietary intake (Nogueira et al., 2004; Burkhart et al., 2016; Burrows et al., 2016) and dietary intake patterns (Burke et al., 2003; Nogueira et al., 2004; Erdman et al., 2013; Noll et al., 2017). In most cases, studies evaluate dietary intake relative to the general population index and do not consider the specific dietary requirements and habits of athletes engaged in high-intensity training programs (Louise et al., 2020). Athletes require a higher intake of energy and nutrients compared to the general population, which can be considered a characteristic of athletes with a high physical activity level.

However, although athletes may require a high energy intake, this is not applicable to all athletes. Despite a sufficient nutritional intake being essential, adapting the diet according to the type of sport is of higher importance. The physical functioning of athletes depends on the type of sport that they practice, and it is important to carefully identify the impact of diet on exercise functions depending on the sport (Główka and Woźniewicz, 2019). This is owing to different muscles and skills being used in different types of sport, together with the proportion of energy used during competition and at certain times within the competition. Considering the distinctive characteristics of each type of sport, different nutritional strategies are required and dietary surveys should be conducted for each type of sport.

As such, dietary surveys and nutrition education specific to the type of sport are essential; this should also apply to wrestling. Wrestling is one of the oldest sports in the world and does not require the use of any tools other than the human body. Wrestling is a high-intensity sport that involves explosive movements for a short period of time; a competition comprises two rounds of three minutes each, for a total of six minutes. Wrestlers do extensive training to maintain their skills and performance, and require approximately 3500-5000 kcal of energy per day due to the high intensity of the sport (Sung-Sook Jo, 2002). Analysing differences in physical functioning based on dietary intake and behaviours to identify the appropriate intake amount can significantly benefit a wrestler's perfoemance and health.

Therefore, dietary surveys and subsequent research on athletic functioning are necessary, although literature on the dietary patterns and athletic performance of wrestlers is limited, especially literature concerning wrestlers performing on a national level and elite wrestlers training in different training environments. Additionally, it is challenging to find a study that analyses wrestlers' habitual diet.

Therefore, the purpose of this study is to investigate the Dietary Patterns and Intake of wrestlers by age and affiliation to determine the percentage of nutrients consumed by athletes, and to investigate the output performance and Blood Lactate Concentration of wrestlers according to the Dietary Patterns and Intake differences. Based on this, the final goal is to identify effective Dietary Patterns and Intake for wrestlers and to provide basic data to maintain athletic function and physical condition.

\section{Methods}

\section{Participants}

This study was conducted among 30 elite wrestlers registered with the Korea Wrestling Association who had more than seven years of experience each. They were grouped according to their competitive level, where they participated as part of the following teams: 1) the national team (nat group, $n=10$ ), 2) the senior 
team (sen group, $\mathrm{n}=10$ ), and 3 ) the university team (uni group, $\mathrm{n}=10$ ). The wrestlers consumed three meals per day and trained for four hours.

The senior team : professional team player who graduated from a university that is not a member of the national team

\section{Ethical approval}

This study was conducted according to the guidelines laid down in the Declaration of Helsinki and all procedures involving human subjects were approved by the research ethics committee at the YongIn University (approval

no.

2-1040966-AB-N-01-20-1911-HSR-166-7). Written consent was obtained from all subjects.

\section{Experimental design}

Prior to participating in this study, the wrestlers agreed to complete a week's (7 days) dietary survey. The study was conducted at the Institute of Exercise Physiology at Yongin University; it included body composition measurement and an anaerobic exercise test. Body composition measurement (InBody 720, InBody Co., Ltd., Seoul, Korea) was conducted at 08:00, and the Wingate test at 8:30 to assess anaerobic power output. The Wingate test (Bar, 1987) with Excalibur sport (Lode B. V., Groningen, Netherlands) comprised performing maximum load exercise (load was specific to body weight. Warm-up was given for $5 \mathrm{~min}$ in an intermittent manner (alternating $30 \mathrm{~s}$ exercise with $30 \mathrm{~s}$ rest). The warm-up was done on a cycle ergometer to promote more specific physiological and motor adaptation. On the command "Start", the subject pedalled as fast as possible without any resistance. It takes 3-4 s to reach maximum speed. Once the maximum speed was achieved, a predetermined load, that is, $7.5 \%$ of body weight in $\mathrm{kg}$ was applied and the participant was coaxed to maintain the pedalling for $60 \mathrm{~s}$. Verbal encouragement was given throughout the test. Any attempt to conserve energy during the last few seconds was discouraged (Figure 1).

Cooling down was done by $2-3 \mathrm{~min}$ of pedalling against a light resistance immediately following the test. The results were obtained in graphical form as in Photo 1 and in numerical values.

The data measured were absolute peak power expressed in Watts (W) and relative peak power expressed in $\mathrm{W} / \mathrm{kg}$.

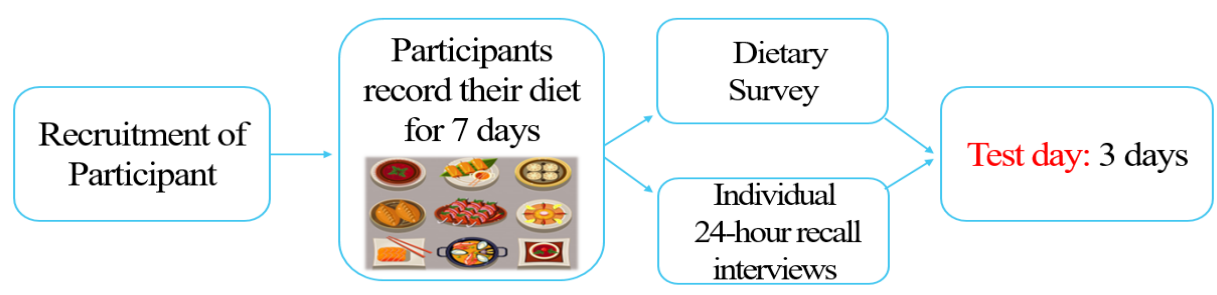

$3 \times$ Test day: Test 10 participact per day

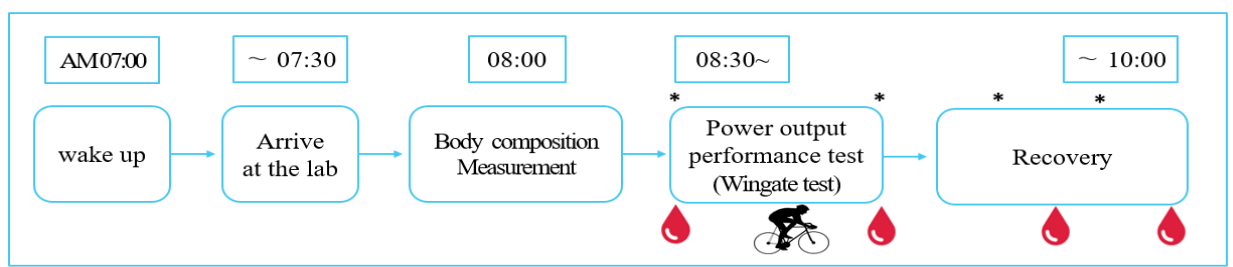

Blood sampling; * Lactate sampling

Figure 1. Diagram illustrating the experimental design 


\section{Dietary survey and analysis}

The dietary survey was conducted for a total of seven days and included all meals and snacks consumed. The athletes photographed all foods consumed, and after 3days the 24-hour recall method was used to assess the food intake amount and type for the week by means of interviews. The investigated dietary intake data were analysed using the CAN-Pro 4.0 software program (Korean Nutrition Society, Seoul, Korea).

Blood sampling and analysis

Blood samples were collected from the brachial vein at four different instances: pre-training, immediately post-training, 20 minutes post training, and 40 minutes post training. Plasma aliquots were stored in a freezer after centrifugation for subsequent analysis. All eight types of blood cells and lipid parameters (Free fatty acids, Triglycerides, Ldl-cholesterol, Hdl-cholesterol ), were analysed by Green Cross Laboratories in Korea.

Blood lactate sampling and analysis

Blood lactate concentrations were also measured at four different instances: pre-training, immediately post-training, 10 minutes post training, and 30 minutes post training. Blood samples were obtained from the finger tips. Lactate concentration was analysed using an electroenzymatic system with a lactate analyser (Lactate Pro 2, Arkray, Kyoto, Japan).

\section{Statistical analysis}

Statistical analyses were performed using SPSS Statistics for Windows version 25.0 (IBM Corp., Armonk, NY). All data are presented as mean \pm SD. One-way ANOVA with post-hoc Tukey-tests was subsequently used to identify after the dietary survey. And Two-way repeated measures ANOVA with

Table 1. Basic characteristics and nutrition intake of participants

\begin{tabular}{|c|c|c|c|c|}
\hline Variable & Nat & Sen & Uni & Recommendation \\
\hline Age(years) & $25.7 \pm 2.4$ & $25.9 \pm 1.6$ & $22.3 \pm 2.7^{\$ \$}$ & NA \\
\hline Height(cm) & $169.6 \pm 3.1$ & $166.5 \pm 6.9$ & $169.1 \pm 6.9$ & NA \\
\hline Body weight(kg) & $71.3 \pm 3.7$ & $69.1 \pm 6.8$ & $69.7 \pm 6.9$ & NA \\
\hline Skeletal muscle mass $(\mathrm{kg})$ & $35.6 \pm 2.8$ & $33.7 \pm 2.9$ & $34.4 \pm 3.8$ & NA \\
\hline Fat mass(kg) & $8.9 \pm 2.3$ & $10.2 \pm 3.7$ & $8.1 \pm 1.8$ & NA \\
\hline Body fat $(\%)$ & $24.9 \pm 1.3$ & $25.2 \pm 1.9$ & $24.4 \pm 1.2$ & NA \\
\hline Body mass index $\left(\mathrm{kg} / \mathrm{m}^{2}\right)$ & $24.8 \pm 1.3$ & $24.6 \pm 2.3$ & $24.3 \pm 1.2$ & NA \\
\hline Carbohydrate(g/day) & $730.3 \pm 121.4$ & $760.3 \pm 140.6^{* *}$ & $679.1 \pm 88.8$ & $8-12 \mathrm{~g} / \mathrm{kg} / \mathrm{d}^{\mathrm{a}}$ \\
\hline Carbohydrate (kcal/day) & $2920.9 \pm 486.5$ & $3041.1 \pm 562.2^{* *}$ & $2716.5 \pm 355.0$ & NA \\
\hline Carbohydrate (En\%) & $55.7 \pm 6.7$ & $60.1 \pm 5.5^{\# \# \#}$ & $54.3 \pm 6.4$ & NA \\
\hline Fat (g/day) & $148.7 \pm 22.8$ & $129.1 \pm 22.9^{\ldots \#}$ & $147.5 \pm 21.6$ & NA \\
\hline Fat (kcal/day) & $1338.2 \pm 204.5$ & $1161.1 \pm 206.2^{\# \#}$ & $1327.7 \pm 194.3$ & NA \\
\hline Fat $(\mathrm{En} \%)$ & $25.5 \pm 3.7$ & $23.1 \pm 3.6^{\# \#}$ & $26.4 \pm 3.3$ & $25-30 \%$ of $E^{b}$ \\
\hline Protein (g/day) & $246.1 \pm 43.1$ & $214.1 \pm 40.4^{\# \#}$ & $243.9 \pm 48.9$ & $1.2-2 \mathrm{~g} / \mathrm{kg} / \mathrm{d}^{\mathrm{a}}$ \\
\hline Protein (kcal/day) & $997.4 \pm 203.0$ & $854.1 \pm 161.6^{\# \#}$ & $977.6 \pm 197.0$ & NA \\
\hline Protein (En\%) & $18.8 \pm 3.2$ & $16.9 \pm 2.5$ & $19.3 \pm 3.4$ & NA \\
\hline Mean Kcal (7days) & $5313.1 \pm 485.3$ & $5112.1 \pm 730.1$ & $5092.1 \pm 373.1$ & NA \\
\hline
\end{tabular}

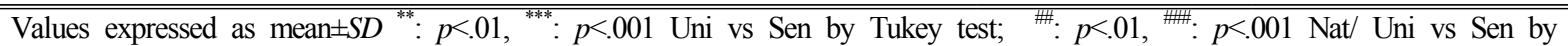
Tukey test; $\$$ : $p<.01 \mathrm{Nat} /$ Sen vs Uni by Tukey test; Nat, National team group; Sen, Senior team group; Uni, University team group; En, Energy; ${ }^{\mathrm{a}}$ source : reference [24]; ${ }^{\mathrm{b}}$ source : reference [15] 
post-hoc Tukey-tests was subsequently used to identify the differences in blood parameters and exercise performance between the groups. A $p<0.05$ was considered statistically significant.

\section{Results}

\section{Baseline demographic characteristics}

The baseline demographic characteristics, including age, height, body weight, and body composition are presented in Table 1. The average age of the athletes

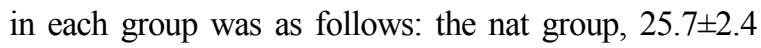
years; sen group, $25.9 \pm 1.6$ years; and uni group $22.3 \pm 2.7$ years.

Only the age and body mass index (BMI) of the participants differed between the groups; the uni group had a significantly lower mean age compared to the other two groups $(p<0.007)$, while the sen group had a significantly higher BMI than the uni group $(p<0.039)$.
In the nat group, the weight and skeletal muscle mass were higher than those of the other groups, although these differences were not significant.

\section{Nutritional intake}

The nutritional intake results are also presented in Table 1. Significant differences in carbohydrate intake were found, with the sen group having had the highest daily carbohydrate intake among the groups (in grams: sen 760.3 \pm 140.6 ; uni $679.1 \pm 88.8, p<0.003$; in kcal: sen $3041.1 \pm 562.2$; uni $2716.5 \pm 355.0, p<0.003)$. In addition, the carbohydrate energy ratio (\%) of the sen group $(60.1 \pm 5.5)$ was significantly higher than that of the other groups (nat 55.7 $\pm 6.7, p<0.002$; uni $54.3 \pm 6.4, p<0.001$ ).

Regarding fat intake, the sen group had the lowest intake, as opposed to the intake of carbohydrates, while the nat group had the highest intake among the groups. The daily fat intake of the nat and uni groups was significantly higher than that of the sen group (in grams:

Table 2. Micronutrient intake of participants and current recommendations

\begin{tabular}{cccccc}
\hline \hline Nutrition ntake & Nat & Sen & Uni & Recommendation & Upper Limit $^{\mathrm{a}}$ \\
\hline Vitamin A (mcg) & $2249.52 \pm 843.82$ & $2473 \pm 784.19$ & $2296.03 \pm 973.63$ & $900 \mathrm{mcg} / \mathrm{d}$ & $3000 \mathrm{mcg} / \mathrm{d}$ \\
Vitamin D (mcg) & $5.33 \pm 3.78$ & $5.08 \pm 2.71$ & $6.64 \pm 4.94$ & $5 \mathrm{mcg} / \mathrm{d}$ & $100 \mathrm{mcg} / \mathrm{d}$ \\
Vitamin E (mg) & $36.83 \pm 12.85$ & $42.27 \pm 11.56$ & $36.67 \pm 13.31$ & $15 \mathrm{mg} / \mathrm{d}$ & $540 \mathrm{mg} / \mathrm{d}$ \\
Vitamin K (mcg) & $428.55 \pm 228.53$ & $500.95 \pm 190.95$ & $423.69 \pm 226.95$ & $120 \mathrm{mcg} / \mathrm{d}$ & $75 \mathrm{mcg} / \mathrm{d}$ \\
Vitamin C (mg) & $\mathbf{1 5 5 . 7 1} \pm \mathbf{4 1 . 5 5}$ & $\mathbf{1 7 9 . 7 9} \pm \mathbf{4 2 . 3 6}$ & $\mathbf{1 5 4 . 6 4} \pm \mathbf{4 5 . 7 5}$ & $90 \mathrm{mg} / \mathrm{d}$ & $2000 \mathrm{mg} / \mathrm{d}$ \\
Vitamin B6 (mg) & $4.66 \pm 0.75$ & $4.59 \pm 0.71$ & $4.61 \pm 0.65$ & $1.3 \mathrm{mg} / \mathrm{d}$ & $100 \mathrm{mg} / \mathrm{d}$ \\
Folate (mcg) & $1034.72 \pm 291$ & $1129.83 \pm 284.25$ & $1046.48 \pm 308.06$ & $400 \mathrm{mcg} / \mathrm{d}$ & $1000 \mathrm{mcg} / \mathrm{d}$ \\
Vitamin B12 (mcg) & $19.65 \pm 10.23$ & $16.26 \pm 9.19$ & $20.55 \pm 10.39$ & $2.4 \mathrm{mcg} / \mathrm{d}$ & $\mathrm{NA}$ \\
Calcium (mg) & $866.95 \pm 197.13 .5$ & $955.27 \pm 172.04$ & $831.95 \pm 171.56$ & $1000 \mathrm{mg} / \mathrm{d}$ & $2500 \mathrm{mg} / \mathrm{d}$ \\
Phosphorus (mg) & $2839.66 \pm 371.54$ & $2781.02 \pm 340.58$ & $2797.67 \pm 329.92$ & $700 \mathrm{mg} / \mathrm{d}$ & $3500 \mathrm{mg} / \mathrm{d}$ \\
Sodium (mg) & $10338.21 \pm 834.95$ & $10419.80 \pm 776.02$ & $10430.32 \pm 764.28$ & $500 \mathrm{mg} / \mathrm{d}$ & $\mathrm{NA}$ \\
Potassium (mg) & $6231.99 \pm 677.35$ & $6374.99 \pm 646.24$ & $6187.81 \pm 469.67$ & $2000 \mathrm{mg} / \mathrm{d}$ & $\mathrm{NA}$ \\
Magnesium (mg) & $221.46 \pm 83.1$ & $\mathbf{2 5 0 . 4 5} \pm \mathbf{7 3 . 1 7}$ & $\mathbf{2 1 6 . 4 8} \pm \mathbf{7 7 . 3 3}$ & $420 \mathrm{mg} / \mathrm{d}$ & $350 \mathrm{mg} / \mathrm{d}$ \\
Iron (mg) & $41.21 \pm 7.64$ & $39.01 \pm 7.39$ & $41.83 \pm 7.90$ & $8 \mathrm{mg} / \mathrm{d}$ & $45 \mathrm{mg} / \mathrm{d}$ \\
Zinc (mg) & $\mathbf{3 4 . 7} \pm \mathbf{8 . 1 3}$ & $\mathbf{2 9 . 9 7} \pm \mathbf{7 . 6 8}$ & $\mathbf{3 6 . 0 4} \pm \mathbf{8 . 8 8}$ & $11 \mathrm{mg} / \mathrm{d}$ & $35 \mathrm{mg} / \mathrm{d}$ \\
Iodine (mg) & $148.44 \pm 56.75$ & $135.52 \pm 49.61$ & $148.10 \pm 55.98$ & $150 \mathrm{mg} / \mathrm{d}$ & $2400 \mathrm{mg} / \mathrm{d}$ \\
Selenium (mcg) & $329.23 \pm 58.48$ & $326.04 \pm 58.67$ & $317.05 \pm 43.32$ & $55 \mathrm{mcg} / \mathrm{d}$ & $400 \mathrm{mcg} / \mathrm{d}$ \\
\hline \hline
\end{tabular}

Values expressed as mean $\pm S D^{*}: p<.05$ Nat, vs Sen by Tukey test; SD ${ }^{\#}: p<.05{ }^{\# \prime}: p<.01$ Uni vs Sen by Tukey test; ${ }^{\mathrm{a}}$ source : reference [25]; ${ }^{\mathrm{b}}$ source : reference [26] 
nat $148.7 \pm 22.8, \quad p<0.001 ; \quad$ sen $129.1 \pm 22.9 ; \quad$ uni $147.5 \pm 21.6, \quad p<0.001$; in $\mathrm{kcal}$ : nat $1338.2 \pm 204.5$, $p<0.001$; sen $1161.1 \pm 206.2$; uni $1327.7 \pm 194.3$, $p<0.001)$. Moreover, the uni group had the highest percentage of fat energy intake, while the intake in both the nat and uni groups was significantly higher than that of the sen group (nat 25.5 $\pm 3.7, p<0.002$; sen 23.1 \pm 3.6 ; uni 26.4 $\pm 3.3, p<0.001)$.

Regarding protein intake, similar to the intake of fat, the sen group had the lowest intake while the nat group had the highest intake among the groups, The daily protein intake of the nat and uni groups was significantly higher compared to that of the sen group (in grams: nat 246.1 $\pm 43.1, p<0.001$; sen $214.1 \pm 40.4$; uni $243.9 \pm 48.9, \quad p<0.003$; in $\mathrm{kcal}$ : nat $997.4 \pm 203.0$, $p<0.001$; sen 854.1 \pm 161.6 ; uni 977.6 $\pm 197.0, p<0.004)$. Furthermore, the uni group had the highest percentage of protein energy intake, while the intake in both the nat and uni groups was significantly higher than that of the sen group (nat 18.8 $\pm 3.2, p<0.007$; sen 16.8 \pm 2.5 ; uni 19.3 $\pm 3.4, p<0.001)$. Finally, considering the mean daily total energy intake (kcal) over the seven days, no significant differences in intake were found (nat 5313.1 \pm 485.3 ; sen 5112.1 \pm 730.1 ; uni 5092.1 \pm 373.1 ).

\section{Blood parameters}

Except for high density lipoprotein cholesterol (HDL-C), no significant differences were found in lipid parameters (free fatty acids, triglycerides, and low density lipoprotein cholesterol) or whole blood cell factors (red blood cells, white blood cells, haemoglobin, haematocrit, mean corpuscular volume, white cell volume, and mean corpuscular haemoglobin concentration) between the groups. The sen group had a significantly higher HDL-C concentration at pre-training, post-training, and 20 minutes post training compared to that of the nat group (Table 2).

\section{Wingate anaerobic test}

The results of the Wingate test are illustrated in Figure 2. Regarding mean power, the nat group had a significantly higher mean power output compared to that of the sen and uni groups (nat 503.4 \pm 27.6 ; sen

Table 3. Complete Blood Cell Type, Fat Index in Blood

\begin{tabular}{|c|c|c|c|c|c|c|c|c|c|c|c|c|}
\hline \multirow{2}{*}{ Variable } & \multicolumn{4}{|c|}{ Nat } & \multicolumn{4}{|c|}{ Sen } & \multicolumn{4}{|c|}{ 'Uni } \\
\hline & Pre & Post & $20 \mathrm{~m}$ post & $40 \mathrm{~m}$ post & Pre & Post & $20 \mathrm{~m}$ post & $40 \mathrm{~m}$ post & Pre & Post & $20 \mathrm{~m}$ post & $40 \mathrm{~m}$ post \\
\hline FFA $(\mu \mathrm{Eq} / \mathrm{L})$ & $298.7 \pm 102.9$ & $252.4 \pm 134.7$ & $258.2 \pm 85.1$ & $209.0 \pm 101.6$ & $304.0 \pm 81.5$ & $205.1 \pm 59.9$ & $260.6 \pm 63.5$ & $225.4 \pm 49.3$ & $318.1 \pm 138.8$ & $232.1 \pm 94.9$ & $235.9 \pm 79.9$ & $200.1 \pm 56.9$ \\
\hline $\mathrm{TG}(\mathrm{mg} / \mathrm{dL})$ & $92.0 \pm 38.3$ & $100.9 \pm 43.4$ & $104.9 \pm 45.5$ & $92.2 \pm 40.6$ & $90.2 \pm 28.5$ & $102.5 \pm 33.3$ & $105.3 \pm 32.2$ & $93.6 \pm 28.6$ & $100.00 \pm 36$ & $107.9 \pm 38.0$ & $112.9 \pm 40.6$ & $104.3 \pm 38.3$ \\
\hline LDL-C (mg/dL) & $102.9 \pm 27.6$ & $112.4 \pm 31.7$ & $103.6 \pm 27.6$ & $101.5 \pm 26.9$ & $110.9 \pm 17.1$ & $123.6 \pm 17.9$ & $113.2 \pm 16.7$ & $111.0 \pm 17.2$ & $100.9 \pm 234$ & $108.9 \pm 22.1$ & $98.7 \pm 20.5$ & $92.9 \pm 20.6$ \\
\hline HDL-C (mg/L) & $59.1 \pm 10.5$ & $64.3 \pm 11.7$ & $62.2 \pm 11.4$ & $60.2 \pm 11.1$ & $75.9 \pm 19.3^{*}$ & $82.5 \pm 19.6^{*}$ & $80.1 \pm 18.8^{*}$ & $77.1 \pm 18.5$ & $62.2 \pm 8.8$ & $68.3 \pm 10.1$ & $65.5 \pm 9.8$ & $71.0 \pm 26.1$ \\
\hline $\mathrm{RBC}\left(10^{6} / \mathrm{L}\right)$ & $5.23 \pm 0.30$ & $5.49 \pm 0.26$ & $5.33 \pm 0.26$ & $5.23 \pm 0.28$ & $5.29 \pm 0.36$ & $5.61 \pm 0.30$ & $5.51 \pm 0.36$ & $5.35 \pm 0.33$ & $5.44 \pm 0.31$ & $5.76 \pm 0.29$ & $5.58 \pm 0.27$ & $5.45 \pm 0.29$ \\
\hline $\mathrm{WBC}\left(10^{6} / \mathrm{L}\right)$ & $6.68 \pm 1.21$ & $9.75 \pm 2.00$ & $8.15 \pm 1.70$ & $5.98 \pm 1.14$ & $7.39 \pm 1.91$ & $11.07 \pm 2.16$ & $8.84 \pm 2.25$ & $6.86 \pm 1.65$ & $7.08 \pm 1.14$ & $10.56 \pm 1.48$ & $8.58 \pm 1.73$ & $6.52 \pm 1.04$ \\
\hline $\mathrm{Hb}(\mathrm{g} / \mathrm{dL})$ & $16.01 \pm 0.90$ & $17.10 \pm 0.61$ & $16.76 \pm 0.78$ & $16.38 \pm 0.64$ & $15.88 \pm 0.76$ & $16.77 \pm 0.79$ & $16.25 \pm 0.80$ & $15.85 \pm 0.84$ & $16.28 \pm 0.96$ & $17.53 \pm 0.85$ & $17.04 \pm 0.81$ & $16.63 \pm 0.81$ \\
\hline Hct $(\%)$ & $46.63 \pm 2.55$ & $50.06 \pm 2.29$ & $48.03 \pm 2.43$ & $46.42 \pm 2.64$ & $46.53 \pm 1.92$ & $50.62 \pm 1.73$ & $49.05 \pm 2.26$ & $46.88 \pm 1.92$ & $48.13 \pm 2.59$ & $52.35 . \pm 2.78$ & $49.99 \pm 2.44$ & $48.07 \pm 2.53$ \\
\hline Platelet $\left(10^{3} / \mathrm{L}\right)$ & \multicolumn{4}{|c|}{$238.80 \pm 45.14$} & \multicolumn{4}{|c|}{$277.60 \pm 46.09$} & \multicolumn{4}{|c|}{$263.00 \pm 31.89$} \\
\hline MCV (fL) & \multicolumn{4}{|c|}{$89.21 \pm 1.93$} & \multicolumn{4}{|c|}{$88.00 \pm 2.71$} & \multicolumn{4}{|c|}{$88.54 \pm 3.59$} \\
\hline $\mathrm{MCH}(\mathrm{pg})$ & \multicolumn{4}{|c|}{$30.64 \pm 1.54$} & \multicolumn{4}{|c|}{$30.02 \pm 1.07$} & \multicolumn{4}{|c|}{$29.77 \pm 1.31$} \\
\hline MCHC (\%) & \multicolumn{4}{|c|}{$34.29 \pm 1.26$} & \multicolumn{4}{|c|}{$34.12 \pm 0.64$} & \multicolumn{4}{|c|}{$33.77 \pm 0.52$} \\
\hline
\end{tabular}

Values expressed as mean $\leqslant S D^{*}: p<.05$ Nat vs Sen by Tukey test; Nat, National team group; Sen, Senior team group; Uni, University team group; Pre, Pre exercise; Post, Post exercise; 20m post, 20minute post exercise; 40m post, 40minute post exercise; FFA, Free fatty acid; TG, Triglyceride; LDL-C, Low density lipoprotein cholesterol; HDL-C, High density lipoprotein cholesterol; RBC, Red blood cell; WBC, White blood cell; Hb, Hemoglobin; Hct, hematocrit; MCV, Mean Corpuscular Volume; MCH, mean corpuscular hemoglobin; MCHC, Mean Corpuscular Hemoglobin Concentra 
$450.3 \pm 47.8, p<0.015$; uni $456.3 \pm 39.8, p<0.032)$. The peak power output was also significantly different between the nat, sen, and uni groups (nat 1234.3 \pm 110.5 ; sen 1095.5 $\pm 147.8, \quad p<0.042$; uni $1045.5 \pm 100.4$, $p<0.005)$. The arrival time to peak power output in the sen group was shorter than that of the nat and uni groups, but this difference was not significant.

Regarding peak power output per exercise duration, after 10 seconds, the following values were recorded: nat 796.9 \pm 85.9 ; sen $694.5 \pm 53.6$; and uni $739.4 \pm 106.7$; a significant difference was found between the nat and sen groups $(p<0.031)$. At 30 seconds, the nat group showed a significant difference in values compared to the sen and uni groups (nat 441.3 \pm 59.2 ; sen $381.8 \pm 42.7$, $p<0.029$; uni $386.5 \pm 42.7, p<0.047)$. Finally, at 60 seconds, the following values were recorded: nat $242.0 \pm 34.2$; sen $228.9 \pm 37.9$; and uni $243.4 \pm 49.2$; these values were not significantly different (Figure 2).

\section{Blood lactate sampling}

The results of the blood lactate analysis, presented in Table 3, revealed a difference in lactate concentration between the sen and uni groups. Post training, the sen group had a significantly higher lactate concentration that the uni group (sen 19.48 \pm 1.28 ; uni 18.02 \pm 1.39 , $p<0.046$ ), while 30 minutes post training, the sen group had a significantly lower lactate concentration than the uni group (sen $2.06 \pm 0.72$; uni $2.84 \pm 0.55, p<0.036$ ), No further significant differences were found.

\section{Discussion}

Carbohydrates as the main energy source for athletes have been shown to have various benefits (Derda 2020). Additionally, adequate glycogen stores are essential for endurance athletes to offset symptoms of fatigue and maintain a high power (Bytomski, 2018; Thomas,
$\mathbf{A}$

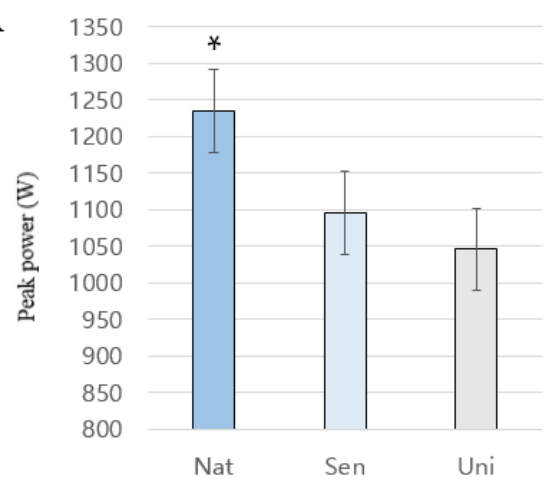

C

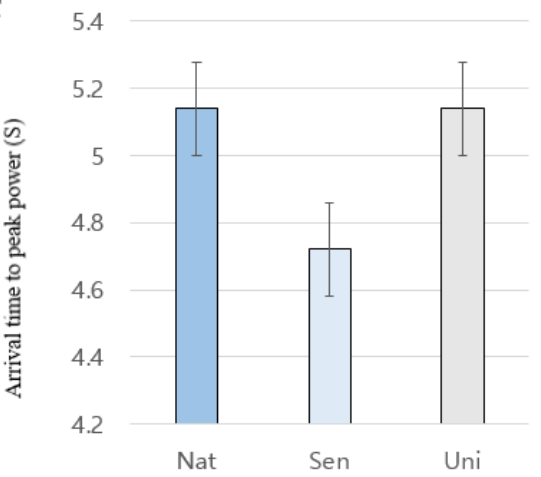

B

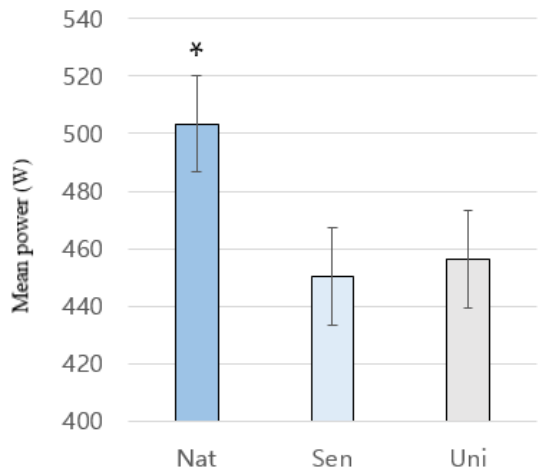

D

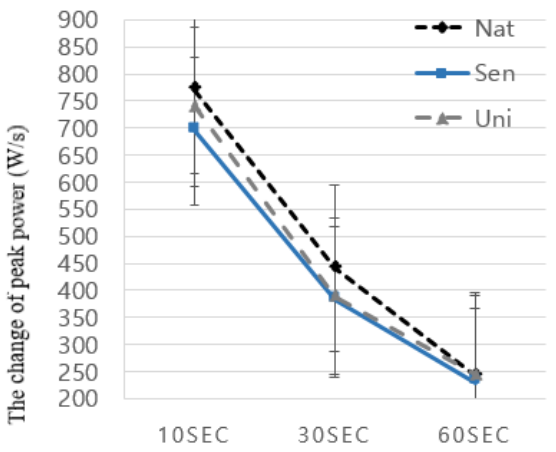

Figure 2. Effect of nutritional intake on exercise performance: (A) peak power, (B) mean power, (C) arrival time to peak power, and (D) change in peak power nat, national team group; sen, senior team group; uni, university team group 
Table 4. Lactate level in Blood

\begin{tabular}{cccc}
\hline \hline Variable & Nat & Sen & Uni \\
\hline Pre exercise $(\mathrm{mmol} / \mathrm{L})$ & $0.96 \pm 0.15$ & $1.07 \pm 0.25$ & $0.94 \pm 0.14$ \\
Post exercise(mmol/L) & $18.92 \pm 1.19$ & $\mathbf{1 9 . 4 8} \pm \mathbf{1 . 2 8}^{*}$ & $\mathbf{1 8 . 0 2} \pm \mathbf{1 . 3 9}$ \\
$10 \min$ Post exercise $(\mathrm{mmol} / \mathrm{L})$ & $6.19 \pm 0.95$ & $5.65 \pm 0.77$ & $6.03 \pm 0.81$ \\
$30 \min$ Post exercise $(\mathrm{mmol} / \mathrm{L})$ & $2.26 \pm 0.69$ & $\mathbf{2 . 0 6} \pm \mathbf{0 . 7 2}$ & $\mathbf{2 . 8 4} \pm \mathbf{0 . 5 5}$ \\
\hline \hline
\end{tabular}

Values expressed as mean $\pm \mathrm{SD}$ *: $P<.05$ Uni vs Sen by Tukey test ; Nat, National team group; Sen, Senior team group; Uni, University teamgroup

2016). The Academy of Nutrition and Dietetics (AND), Dietitians of Canada (DC), and American College of Sports Medicine (ACSM) recommend that moderate to high intensity exercise (1-3 hours per day) mandates $6-10 \mathrm{~g} / \mathrm{kg} / \mathrm{d}$ of carbohydrates, while ultra-endurance athletes with extreme levels of daily activity (4-5 hours of moderate- to high-intensity exercise per day) may need up to $8-12 \mathrm{~g} / \mathrm{kg} / \mathrm{d}$ (Jäger et al., 2017; Kenneth \& Andrew, 2019).

Wrestling comprises high-intensity exercise that consumes over $5000 \mathrm{kcal} / \mathrm{d}$, and wrestlers need to consume $8-12 \mathrm{~g} / \mathrm{kg} / \mathrm{d}$ of carbohydrates to allow for training longer than 4 hours per day. In this study, all three groups of wrestlers consumed approximately 700 $\mathrm{g}$ of carbohydrates daily (mean weight: $70 \mathrm{~kg}$ ). In the case of the sen group, carbohydrate intake constituted $60 \%$ of the total energy intake, which is in line with traditional Korean dietary habits considering the reliance on rice. Conversely, the nat and uni groups, with a carbohydrate consumption of less than $60 \%$, revealed more westernized dietary habits.

At present, the Korean diet is rapidly westernizing, with the general population as well as athletes consuming increasing amounts of protein and fat. Protein is an essential nutrient for athletes, especially for athletes who continuously train, and a high protein intake has been shown to increase muscle size and muscle fibre cross-sectional area (Buckner et al., 2017), as well as improve strength and exercise performance (Robert et al., 2017). According to Thomas et al. (2016) and Phillips et al. (2011), strength/power athletes are typically advised to consume protein at levels relating to the higher end of the range, while the temporary consumption of even higher quantities during intense training periods may provide additional benefits. In this study, the nat group had the highest daily protein intake (in grams and kcal) and revealed the highest anaerobic power output among the three groups. However, in the case of the uni group, despite also having a high protein intake, the same power output results as found in the nat group were not obtained. This may be due to power output not only being affected by protein intake, but possibly also by training time and the experience of the athlete. Therefore, in order to find out the effect of protein intake on power output, a follow-up study is needed to determine the relationship between protein intake and exercise experience and protein. According to the AND, DC, and ACSM, the recommended protein intake for athletes is in the range of $1.2-2.0 \mathrm{~g} / \mathrm{kg} / \mathrm{d}$ (Jäger et al., 2017; Vitale \& Getzin, 2019). It has previously been confirmed that wrestlers consume higher levels of protein. High-protein diets have been associated with the risk of kidney stone formation (Fink et., al 2009); therefore, it is imperative to consume the adequate amount of protein, although accurate nutrition information and education for athletes are still lacking.

Fat is an essential component of an athlete's diet, and its intake should constitute no less than $20 \%$ of the total caloric intake (Bytomski, 2018; Casazzaet et., al 2018). Even n-3 polyunsaturated fatty acids have recently been suggested as a supplement to improve exercise performance and recovery (Boit et al., 2017). Fat is a worthy fuel source for endurance athletes, although it has less importance for strength/power 
athletes (Wilmore et al., 2008). This study revealed a difference in the amount of fat consumed by the athletes in the different groups, although all the athletes consumed adequate amounts.

In this study, the sen group had a significantly higher lactate concentration after training in comparison with the other two groups. Blood lactate levels are indicative of aerobic endurance and correlates strongly with heart rate variability (Papassotiriou et al., 2018). The sen group revealed a lower power output compared to the other groups, and it is believed that the difference in lactate concentration occurred during recovery. Power output may have also been affected by the increased lactate concentration owing to the consumption of carbohydrates. According to Lecoultre et al. (2010), the additional intake of carbohydrates for athlete may increase lactate levels, and similar results have been found in this study. However, there are many shortcomings in evaluating lactate recovery ability only with the diet consumed. Therefore, it is necessary to study the difference in lactate recovery of wrestlers according to the degree of diet intake in various wrestlers ages.

The limitations of this study include that the number of participants was small and limited to wrestlers. Furthermore insufficient information was gathered on the eating environment of each athlete. this should be evaluated by means of a follow-up study based on this study. In addition, the differences between dietary patterns in the same group should be analysed to determine the exact impact of diet and motor functions. Finally, we failed to analyze the causal relationship between Dietary Patterns and Intake on Output Performance and Blood Lactate Concentration. Therefore, as a follow-up study, it considered that it is necessary to study how athletes' eating habits affect exercise ability and lactic acid recovery.

In conclusion, the aim of this pilot study was to examine the nutritional intake of Korean wrestlers and, based on this, assess the changes in lipid parameters, blood lactate concentration, and the effects on power output performance. We found that the nutritional intake of Korean wrestlers meets the recommended standards, although the macronutrient intake differed between the groups. In addition, despite finding differences in power output performance, follow-up studies may reveal more accurate associations between nutritional intake, diet quality, and performance. Finally, considering a study concerning nutrition and weight loss, including not only wrestlers but also combat sport athletes will positively impact nutrition education as well as athletes' intake and performance.

\section{Acknowledgments}

Junghoon-Lee, Dongheuk-Park; performed experiments. All authers declare taht they have no confict of interest. We would like to thank Editage (www.editage.co.kr) for English language editing.

\section{References}

Bar-Or, O. (1987). The Wingate anaerobic test an update on methodology, reliability and validity. Sports Medicine, 4(6), 381-394.

Burkhart, S. J., \& Pelly, F. E. (2016). Dietary intake of athletes seeking nutrition advice at a major international competition. Nutrients, 8(10), 638.

Burke, L. M., Slater, G., Broad, E. M., Haukka, J., Modulon, S., \& Hopkins, W. G. (2003). Eating patterns and meal frequency of elite Australian athletes. International Journal of Sport Nutrition and Exercise Metabolism, 13(4), 521-538.

Buckner, S. L., Jessee, M. B., Mattocks, K. T., Mouser, J. G., Counts, B. R., Dankel, S. J., \& Loenneke, J. P. (2017). Determining strength: a case for multiple methods of measurement. Sports Medicine, 47(2), 193-195.

Burrows, T., Harries, S. K., Williams, R. L., Lum, C., \& Callister, R. (2016). The diet quality of competitive adolescent male rugby union players with energy balance estimated using different physical activity 
coefficients. Nutrients, 8(9), 548.

Bykowska-Derda, A., Czlapka-Matyasik, M., Kaluzna, M., Ruchala, M., \& Ziemnicka, K. (2020). Diet quality scores in relation to fatness and nutritional knowledge in women with polycystic ovary syndrome: case-control study. Public Health Nutrition, 1-10.

Bytomski, J. R. (2018). Fueling for performance. Sports health, 10(1), 47-53

Capling, L., Tam, R., Beck, K. L., Slater, G. J., Flood, V. M., O’Connor, H. T., \& Gifford, J. A. (2021). Diet Quality of Elite Australian Athletes Evaluated Using the Athlete Diet Index. Nutrients, 13(1), 126.

Casazza, G. A., Tovar, A. P., Richardson, C. E., Cortez, A. N., \& Davis, B. A. (2018). Energy availability, macronutrient intake, and nutritional supplementation for improving exercise performance in endurance athletes. Current Sports Medicine Reports, 17(6), 215-223.

Da Boit, M., Hunter, A. M., \& Gray, S. R. (2017). Fit with good fat? The role of $n-3$ polyunsaturated fatty acids on exercise performance. Metabolism, 66, 45-54.

Erdman, K. A., Tunnicliffe, J., Lun, V. M., \& Reimer, R. A. (2013). Eating patterns and composition of meals and snacks in elite Canadian athletes. International Journal of Sport Nutrition and Exercise Metabolism, 23(3), 210-219.

Fink, H. A., Akornor, J. W., Garimella, P. S., MacDonald, R., Cutting, A., Rutks, I. R., ... \& Wilt, T. J. (2009). Diet, fluid, or supplements for secondary prevention of nephrolithiasis: a systematic review and meta-analysis of randomized trials. European Urology, 56(1), 72-80.

Główka, N., \& Woźniewicz, M. (2019). Potential use of Colostrum Bovinum supplementation in athletes-A review. Acta Scientiarum Polonorum Technologia Alimentaria, 18(2), 115-123.

Jäger, R., Kerksick, C. M., Campbell, B. I., Cribb, P. J., Wells, S. D., Skwiat, T. M., ... \& Antonio, J. (2017). International society of sports nutrition position stand: protein and exercise. Journal of the International Society of Sports Nutrition, 14(1), $1-25$.

Lecoultre, V., Benoit, R., Carrel, G., Schutz, Y., Millet, G. P., Tappy, L., \& Schneiter, P. (2010). Fructose and glucose co-ingestion during prolonged exercise increases lactate and glucose fluxes and oxidation compared with an equimolar intake of glucose. The American Journal of Clinical Nutrition, 92(5), 1071-1079.

Nogueira, J. A., \& Da Costa, T. H. (2004). Nutrient intake and eating habits of triathletes on a Brazilian diet. International Journal of Sport Nutrition and Exercise Metabolism, 14(6), 684-697.

Noll, M., de Mendonça, C. R., de Souza Rosa, L. P., \& Silveira, E. A. (2017). Determinants of eating patterns and nutrient intake among adolescent athletes: a systematic review. Nutrition Journal, 16(1), 1-11.

Papassotiriou, I., \& Nifli, A. P. (2018). Assessing performance in pre-season wrestling athletes using biomarkers. Biochemia Medica, 28(2), 318-328.

Phillips, S. M., \& Van Loon, L. J. (2011). Dietary protein for athletes: from requirements to optimum adaptation. Journal of Sports Sciences, 29(sup1), S29-S38.

Sung-Sook Jo. (2002). Sports nutrition. Seoul, Hyoil.

Thomas, D. T., Erdman, K. A., \& Burke, L. M. (2016). Position of the Academy of Nutrition and Dietetics, Dietitians of Canada, and the American College of Sports Medicine: nutrition and athletic performance. Journal of the Academy of Nutrition and Dietetics, 116(3), 501-528.

Vitale, K., \& Getzin, A. (2019). Nutrition and supplement update for the endurance athlete: review and recommendations. Nutrients, 11(6), 1289.

Wilmore, J. H., Costill, D. L., \& Kenney, W. L. (2008). Fuel for exercising muscle: metabolism and hormonal control. Physiology of Sport and Exercise. 4th ed. Champaign Illinois: Human Kinetics, 48-59. 